\title{
DRAMATIC DECREASE IN MUSCULAR FITNESS IN CZECH SCHOOLCHILDREN OVER THE LAST 20 YEARS
}

\author{
Dana Müllerová1, Jana Langmajerová1, Pavel Sedláček ${ }^{1}$, Jana Dvořáková1, Tomáš Hirschner², Zdeněk Weber ${ }^{3}$, \\ Luděk Müller ${ }^{4}, Z^{\prime}$ uzana Derflerová Brázdová5 \\ 'Department of Public Health and Preventive Medicine, Medical Faculty in Pilsen, Charles University in Prague, Pilsen, Czech Republic \\ 2Pilsen Sport Company, Pilsen, Czech Republic \\ ${ }^{3}$ West Bohemia University in Pilsen, Czech Republic \\ ${ }^{4}$ European Centre of NTIS West Bohemia University in Pilsen, Faculty of Applied Sciences, Pilsen, Czech Republic \\ ${ }^{5}$ Department of Public Health, Faculty of Medicine, Masaryk University, Brno, Czech Republic
}

\section{SUMMARY}

Aim: Obesity and physical inactivity had already reached epidemic, becoming one of the leading causes of death and disability worldwide. The objective of this study was to investigate the current level and a nearly three decades' trend of muscular fitness (MF) and the nutritional state of Czech children.

Methods: In 2013, cross-sectional epidemiological survey was conducted in schoolchildren with examination of the anthropometric characteristics and measured MF using a UNIFIT test, which normative for MF categories was given as results of national monitoring data collected in 1987. In total 896 current schoolchildren (472 aged 8-9 years and 424 aged 12-13 years) were examined from selected children through stratified sampling from the Czech Republic.

Results: Against 31\% of children from 1986 there were $74 \%$ of current children classified as "poor" or "below normal" in the MF category $(p<0.001)$. MF was inversely associated with BMI. Poor posture was diagnosed in $24 \%$ of children, more frequently in overweight (OW) and obese (OB) children in comparison to normal body weight children $(p<0.001)$. In comparison to $10 \%$ of OW and OB children in 1991, using these cut-off points for body mass index references, the current prevalence of OW and OB doubled (19.8\%).

Conclusions: Current Czech schoolchildren showed a doubled prevalence of OW and OB during the last two decades and simultaneously during nearly three decades there were more than doubled prevalence of "poor" or "under normal" MF of children, with overall dramatic decrease of MF in current schoolchildren.

Key words: muscular fitness, obesity, children, posture

Address for correspondence: D. Müllerová, Charles University in Prague, Faculty of Medicine in Pilsen, Department of Public Health and Preventive Medicine, Lidická 4, 30166 Plzeň, Czech Republic. E-mail: Dana.Mullerova@lfp.cuni.cz

\section{INTRODUCTION}

By the end of the century, obesity (OB) had already reached epidemic proportions, becoming one of the leading causes of death and disability worldwide (1). WHO emphasizes that $44 \%$ of the diabetes burden, $23 \%$ of the ischaemic heart disease burden and around $7-41 \%$ of certain cancer burdens are attributable to overweight (OW) and OB (2). Adults in the Czech Republic have one of the highest prevalence of $\mathrm{OB}$ and OW among all European countries. A research conducted in 2008-2009 on a representative sample of Czech population $(n=2,058)$ suggests that $23 \%$ of adult population of the Czech Republic are obese and 34\% are overweight (3). The increase of prevalence of OW and $\mathrm{OB}$ during childhood is one of causes of this increase in OB in adulthood. There are several different classifications of $\mathrm{OB}$ in children. The most commonly used is the criteria set forth by IOTF or WHO (4, 5). Every ten years from 1951 until 2001, the Czech Republic has collected the data from anthropometric children's measurements. The aim of these studies was to construct national reference data.
The BMI references are based on the Nationwide anthropological survey $1991(6,7)$.

The progression to the obesity pandemic, starting from the 1970 's, is explained by the dramatic change in human behaviour, especially due to the decrease of physical activity (PA) and the change in dietary habits. However, PA is essential for long- and short-term physical and mental health. The loss of PA is associated with metabolic inflexibility and decrease of energy expenditure, a status prone to develop overweight and obesity with its co-morbidities, deterioration of cardiorespiratory, postural and psychological functions. WHO has advised children should not have more than 1-2 hours of quality television and/or screen time per day and undertake at least 60 minutes of moderate-tovigorous PA. However, the crucial for health benefit - current and future health status - is not self-reported time of PA, but objective measured physical fitness. Health related physical fitness encompasses cardio-respiratory fitness, muscular fitness (MF) and body composition, mutually influencing each other. Cardio-respiratory fitness is traditionally measured by spiroergometry. MF is possible 
to evaluate by the examination of muscular endurance, strength and postural function of muscular-skeletal system. Unfortunately, the vast preponderance of studies examining nutritional state of children collect only data about hours spent doing PA/or screen table watching. There is a limited number of studies testing and comparing the status of children's MF.

The aim of this paper was to determine the level of MF and prevalence of OW and OB in two age categories of schoolchildren measured in 2013 and to compare them with the results obtained by the national survey of MF from 1987, and by the national anthropometrical survey performed in 1991. To the best of our knowledge, no recent study to date has examined MF in an extended sample of Czech children and detected the long-term trend.

\section{MATERIALS AND METHODS}

The data of objective measured MF, anthropometric parameters (body weight, body height and waist circumference), postural function, together with subjective reported data about PA/ screen table watching and subjective symptoms (headache and back pain) of 8-9 years old children (younger girls Gy; younger boys By) and 12-13 years old children (older girls Go, older boys Bo) were collected in 2013. The data are representative for the Czech Republic. Through two-stage stratified sampling method there were randomly selected children from the Pilsner region, one of the fourteen regions in the Czech Republic, with territory of $7,500 \mathrm{~km}^{2}$, total number of inhabitants 575,000 . There are 194 various public schools, with total number of schoolchildren 41,614 aged 6-15 years. Participating 80 school classes were randomly selected according to the district and size of residential location. According to the size of residential location the children were categorized into three groups - urban ( $>50,000$ inhabitants), semi-urban ( $>5,000$ inhabitants) and rural $(\leq 5,000$ inhabitants). The study included all pupils from randomly selected school classes, who have permission of pediatrician to attend compulsory physical education and were not ill during the time of survey. Of these children, only the children whose parents signed the informed consent (response rate 45\%) participated in the examination. For long-term trend evaluation, the data of cohorts of the same age as the children examined in 2013 was used. It was the national survey of physical development and MF of children from former Czechoslovakia (age 7-18 years) performed in 1987, and the Czech national anthropometric survey (age 0-18 years) conducted in $1991(6,7)$.
Anthropometric measurements included height, body weight, waist and hip circumference. Weight was measured to the nearest $0.1 \mathrm{~kg}$ with the same kind of portable scale, with the participant in minimal clothing. Height was measured to the nearest $0.1 \mathrm{~cm}$ without shoes. Body mass index (BMI) was calculated as body weight $(\mathrm{kg})$ divided by height squared $\left(\mathrm{m}^{2}\right)$. Waist circumference (WC) was measured with a tape at the mid-distance between the top of the iliac crest and the bottom of the rib cage. BMI was categorized according to the Czech reference growth charts BMI for age, from 1991, where cut-off points were established for OW as the values of $90^{\text {th }}$ percentile and higher; for $\mathrm{OB}$, those of $97^{\text {th }}$ percentile and higher were used.

The level of MF was assessed using motor performance tests. These tests (T1: standing broad jump, T2: sit-ups 60 seconds and T3: shuttle run $4 \times 10 \mathrm{~m}$ ) were selected from the UNIFITTEST test battery (6-60) (8) with standardized scale based on the data distribution from a nationwide representative survey from 1987 (Table 1). Each child was rated using a ten point standardized scale for each test (10). The classification in particular tests is as follows: "poor" 1-2, "below normal" 3-4, "normal" 5-6, "above normal" 7-8, "excellent" 9-10. The test battery score was calculated from the sum of points obtained in all three tests. Classification in score of battery (e.g. T1+T2+T3) was categorised as "poor" 3-10, "below normal" 11-14, "normal" 15-18, "above normal" 19-22, and "excellent" 23-30. An average Battery Score for each of the four gender and age specified groups was calculated using the cumulative total results from all of the children within each respective group, and then a subsequent average was calculated. The second evaluation represents the 5 Fitness Level categories (poor, below average, average, above average, and excellent defined from 1987) and the distribution of each current child's fitness level results within their own respective group.

The posture of children was evaluated using "the Matthias posture test", clinical test to detect posture changes in children and adolescents. The examined child must endure in actively upright position, (arms outstretched) for 30 seconds. If the head bent forward and the upper chest tilts, arm falling and the belly is pushed out, they are signs of poor posture. In serious cases the child is unable to take correct input posture (10).

Examination was completed by self-reported headache, or back pain. All participants were invited to complete a self-reported questionnaire designed to assess PA. Subjects were asked two types of questions in order to assess PA/exercise and sedentary levels on a weekly basis through self-assessment of the weekly amount of time spent on walking and organized exercise, i.e. in gyms or sport centres; and self-evaluation of the time spent on

Table 1. Characteristics of individual tests, examining together muscular fitness

\begin{tabular}{|l|l|l|l|}
\hline Title test & Description of test & Factor, capability & Score \\
\hline $\begin{array}{l}\text { T1 test: } \\
\text { Shuttle run } 4 \times 10 \mathrm{~m}\end{array}$ & $\begin{array}{l}\text { A running and turning (shuttle) test at } \\
\text { maximum speed }\end{array}$ & Running speed, agility & $\begin{array}{l}\text { Time needed to complete four cycles } \\
\text { is the score and written in tenths of } \\
\text { second }\end{array}$ \\
\hline $\begin{array}{l}\text { T2 test: } \\
\text { Standing broad jump }\end{array}$ & $\begin{array}{l}\text { Jumping for distance from a standing } \\
\text { start }\end{array}$ & Dynamic explosive strength & $\begin{array}{l}\text { The better of the two attempts is the } \\
\text { score* }\end{array}$ \\
\hline $\begin{array}{l}\text { T3 test: } \\
\text { Sit-ups }\end{array}$ & $\begin{array}{l}\text { Maximum number of sit-ups achievable } \\
\text { in } 60 \text { seconds }\end{array}$ & Trunk strength (muscular endurance) & $\begin{array}{l}\text { The total number of correctly performed } \\
\text { complete sit-ups in } 60 \text { seconds is the } \\
\text { score }\end{array}$ \\
\hline
\end{tabular}

*results given in $\mathrm{cm}$ 
TV watching, with computer or at a school requiring sedentary (sitting) time, as well as time spent for entertainment.

In 2013, the survey was performed by experienced medical students and physical training instructors received standardised training on anthropometric techniques and UNIFITTEST by physicians, who followed standardized criteria, in order to be able to take measurements of children during their physical education classes at schools. The survey was approved by the Ethics Committee of the Medical School and Faculty hospital in Pilsen and was supported by the Pilsen regional authority and Educational Institute of the Pilsen region.

\section{Statistical Analysis}

The non-response rate (including incorrect values) for the variables included in the analysis was $55 \%$.

The correlation between the BMI values and their corresponding muscular fitness categories values was calculated for each age and gender specified group of participants and, in addition, for the whole set of these groups. Because we cannot assume that neither BMI nor the muscular fitness categories values have a normal distribution, the Kendall's correlation coefficient RhoK (instead of usually used Pearson's correlation coefficient, RhoP), which is based on order statistics was calculated for each correlation $(11,12)$. Finally, a statistical test that the correlation is significantly different from zero was performed for all these correlation coefficients. Furthermore, statistical analysis using the Wilcoxon signed rank test was performed to compare the MF values between groups of participants grouped according to the participant's BMI value. This test was done for each age-gender specified groups. All statistical computations were performed with the MATLAB Statistics Toolbox. The values of $\mathrm{p}<0.05$ were taken as statistically significant.

\section{RESULTS}

The prevalence of OW and OB in 8-9 year-old and 12-13 yearold girls and boys in 2013 was $16.1 \%$ and $20.1 \%$, respectively. OB was present in $10 \%$ of girls, and $9 \%$ of boys. In comparison to $10 \%$ of OW and OB children in 1991, using these cut-off points for body mass index references, the total current prevalence of OW and OB doubled, resulting in 19.8\% (Fig. 1).
More details of the sample's anthropometric characteristics and results of MF testing are presented in Table 2.

Regarding MF using normative for UNIFIT test from 1986 there were only $26 \%$ of subjects examined in 2013 showing "normal", "above normal", and "excellent" MF. The rest of the sample - $74 \%$ of current children ( $74 \%$ overall, $73 \%$ in boys, $74 \%$ in girls) was classified as "below average" or "poor" in MF. Results show a statistical significant increase in proportion of children classified as "below normal" or "poor" in MF category in 2013 compared to $1986(\mathrm{p}<0.001)$ in all examined groups of children.

MF was inversely associated with BMI with exception of younger girls. The Kendall's correlation coefficient RhoK between BMI and MF in the set of all participants: $\mathrm{RhoK}=0.0741$ $(\mathrm{p}<0.01)$; in younger girls $(\mathrm{Gy})$ : $\mathrm{RhoK}=0.0970(\mathrm{p}=0.057)$; in younger boys $(\mathrm{By})$ : $\mathrm{RhoK}=0.1443(\mathrm{p}<0.01)$; in older girls (Go): $\mathrm{RhoK}=0.1196(\mathrm{p}<0.05)$; and in older boys $(\mathrm{Bo})$ : $\mathrm{RhoK}=$ $0.2428(\mathrm{p}<0.001)$. MF of OW and OB children was worse than MF of normal weight $(\mathrm{NW})$ children in total $(\mathrm{p}<0.05)$, or in each age-gender specified group: $\mathrm{Gy}(\mathrm{p}<0.01)$; Go $(\mathrm{p}<0.01)$; By $(p<0.001)$; Bo $(p<0.001)$. Underweight (UW) Gy had a lower (i.e. worse) value of MF than NW ( $<<0.05)$ (Fig. 2).

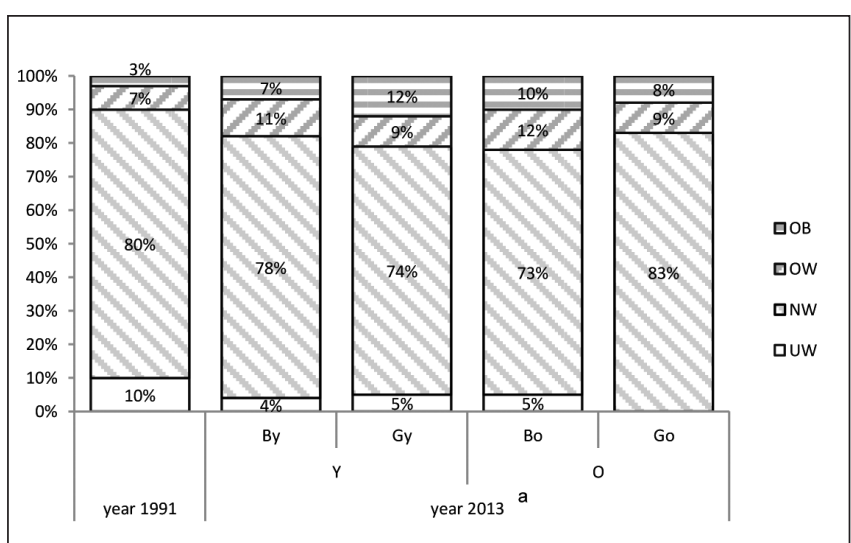

Fig. 1. The increase of $O B$ and $O W$ prevalence in Czech children from the 1991 to 2013.

aln 2013 there were used cut off points for BMI references from the Czech Republic given in the Nationwide Anthropological Survey (NAS) from $1991(6,7)$. Gy - younger girls; By - younger boys; Go - older girls; Bo - older boys; NW - normal weight; O - older children; OB - obesity; OW - overweight; UW - underweight, $\mathrm{Y}$ - younger children.

Table 2. Sample's anthropometric and muscular fitness characteristics

\begin{tabular}{|c|c|c|c|c|c|c|c|c|}
\hline \multirow{2}{*}{ Characteristics } & \multicolumn{2}{|c|}{ Younger girls (8-9 years) } & \multicolumn{2}{|c|}{ Older girls (12-13 years) } & \multicolumn{2}{|c|}{ Younger boys ( $8-9$ years) } & \multicolumn{2}{|c|}{ Older boys ( $12-13$ years) } \\
\hline & $x$ & SD & $x$ & SD & $\mathbf{x}$ & SD & $x$ & SD \\
\hline Body weight (kg) & 28.5 & 5.0 & 46.4 & 9.2 & 29.8 & 5.8 & 48.3 & 10.4 \\
\hline Body height (cm) & 130.9 & 5.9 & 155.7 & 7.7 & 132.5 & 6.2 & 156.9 & 7.8 \\
\hline $\mathrm{BMI}\left(\mathrm{kg} \cdot \mathrm{m}^{-2}\right)$ & 16.6 & 2.2 & 19.0 & 2.9 & 16.9 & 2.5 & 19.5 & 3.3 \\
\hline Waist circumference $(\mathrm{cm})$ & 56.8 & 6.3 & 64.6 & 7.1 & 58.8 & 5.6 & 70.1 & 8.8 \\
\hline T1 test (Scale 1-10) & 3.6 & 2.2 & 4.1 & 2.2 & 3.6 & 2.3 & 3.7 & 2.1 \\
\hline T2 test (Scale 1-10) & 3.9 & 2.0 & 4 & 2.0 & 4.1 & 2.1 & 3.9 & 1.9 \\
\hline T3 test (Scale 1-10) & 2.8 & 1.8 & 3.9 & 1.7 & 2.9 & 1.7 & 4.6 & 1.8 \\
\hline Battery score* (Scale 1-30) & 10.3 & 4.7 & 12.1 & 4.9 & 10.6 & 4.8 & 12.2 & 4.8 \\
\hline
\end{tabular}

${ }^{*}$ According to UNIFIT test result and achieved battery score (BS) during 3 physical tests (T1+T2+T3) muscular fitness categories are classified as poor (BS 3-10), below normal (BS 11-14), normal (BS 15-18), above normal (BS 19-22), and excellent (BS 23-30).

$\mathrm{SD}$ - standard deviation; $\mathrm{x}$ - average 


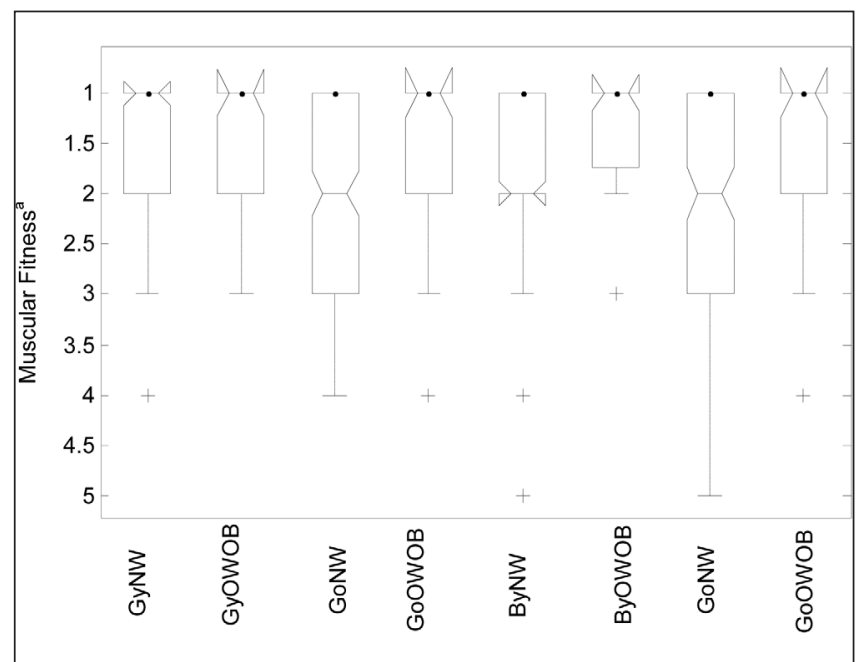

Fig. 2. Muscular fitness (expressed as Box plot) for each examined group characterised by gender, age, and nutritional status.

aMF categories according to UNIFIT test: 1 - poor; 2 - below normal; 3 -normal; 4 - above normal; 5 - excellent.

Bo - older boys; By - younger boys; Go - older girls, Gy - younger girls; MF muscular fitness; NW - normal weight; OB - obesity; OW - overweight.

Poor posture was diagnosed in $24 \%$ of children, more frequently in $\mathrm{OW}$ and $\mathrm{OB}$ children in comparison to normal body weight children $(\mathrm{p}<0.001)$. The most frequently reported subjective problems of the study population was headache $(13.75 \%$ overall, $12 \%$ in boys, $15.5 \%$ in girls), followed by back pain $(9 \%$ overall, $7.5 \%$ in boys, $10.5 \%$ in girls).

Concerning PA parameters, subjects self- reported longer time spent by physical activity (vigorous or moderate level) during weekend in comparison to weekdays; 2.47 hours/weekend day, 1.17 hours/weekday. There was an increase of inactivity in older children, especially boys, who spent more time in front of computer.

\section{DISCUSSION}

The increase of OB and OW in Czech children since the 1950's is shown by the results of other studies (13). In our study the cut off points for BMI references from the Czech Republic given in the Nationwide Anthropological Survey (NAS) from 1991 were used. According to results from Kunešová et al., these Czech cut off point criteria are softer in comparison to the IOTF or WHO criteria, and thus the prevalence of OB or OW is lower in comparison to other ones (14). However, our results of OB and OW in younger children from 2013 are worse in comparison to data provided by Kunešová et al. from 2008 (14.8\% in boys, $11.1 \%$ in girls).

This cross-sectional study is the first one to report on the shift of fitness level and nutritional state of current children using cut off normative 2 decades ago. It is proved that only $26 \%$ of children match criteria of "normal" level of MF and OB and OW doubled in comparison to 1991. The shift to the decreased fitness level of children beginning in the 1970's could be explained by the dramatic change in their environment, along with the development of new technologies. In children, the causes of physical passivity are associated with or a result of watching TV, playing on or overusing the computer, mobile games etc., including internet communication (15). This represents for children a very new and attractive mode of social communication and creating and experiencing relationships without the need of physical activity.

This study also confirmed an inverse association between MF and total adiposity, which is in concert with results of metaanalysis by Smith JJ et al. (16). This meta-analysis also found strong evidence for an inverse association between MF and CVD and metabolic risk factors, bone health and self-esteem of children and adolescents. Simultaneously, we have found a large proportion of non physiological posture keeping, associated with subjective symptoms like headache and back pain.

According to the self-reported data, younger children in our study in average met the WHO recommendation to have less than 1-2 hours of quality television and/or screen time per day and undertake at least 60 minutes of moderate-to-vigorous physical activity. However, the evidence suggests that their MF is, in comparison to the level of children from 1986, dramatically worse. There was an increase of MF with age although there was simultaneously an increase of numbers of hours weekly spent in front of computer or watching TV. We believe that this discrepancy between WHO recommendations and the real state of MF in children could be explained partly by overestimation of PA in self reporting of children, partly by disappearance or shortening of their spontaneous PA. This as well shows the methodological problem of physical fitness assessment, which is based on collection of self-reported data about PA only.

The advancement of modern technology has allowed children to become more and more sedentary. The convenience of nearly all aspects of computers, social media, communication, etc., has created an environment of children comfortable when being passive or lazy. We are missing the times when children desired to go outside and play with friends or to physically travel to other houses or neighbourhoods to engage in multiple types of physical-related play. The level of happiness and satisfaction that these children experienced from spontaneous PA is now nearly completely lost and non-existent due to the comfort of simply sitting on a chair at home in front of the computer or TV.

Moreover, the Czech Republic has one of the highest prevalence of OW and OB in adults among all European countries. Unfortunately, obese parents in the Czech Republic do not consider their obesity and their children's obesity a problem. Because of this, the parents do not create an active lifestyle suitable for maintaining a healthy weight and fitness level. Along with this, the parents are looking for ways of how to excuse or clear their children from being involved in any type of PA. In the Czech Republic, two hours of physical exercise classes per week are required. These 2 hours are mandatory for all students. And starting in 2015, this number should be increased to 3 hours per week. It is also important to mention that twenty years ago all club and team sports for children were cost-free for all participants. Nowadays, there are greater costs involved for all parents of children involved in any sport activity.

\section{CONCLUSION}

This cross-sectional study is the first one to report on the shift of MF level and nutritional state of current children using cut off 
normative from 27 years ago. There is a proof that only $26 \%$ of children match the criteria for "normal" or better level of physical fitness, while in 1986 it was $69 \%$ of children. Simultaneously, OB and OW prevalence doubled in comparison to 1991. In addition, there was a large proportion of non-physiological posture keeping associated with subjective symptoms like headache and back pain in OB and OW children.

An inverse association between MF and BMI was presented, where the best level of MF showed children with normal nutritional state. In boys, there was an increase in MF with age, although there was simultaneously an increase in the number of hours spent daily in front of a computer or watching TV.

\section{Acknowledgements}

Authors thank to the Regional Authority of the Pilsen Region for its sponsorship of this study and Mr. Derek VanReenan for his kind text reading and correction

\section{REFERENCES}

1. Frühbeck G, Toplak H, Woodward E, Yumuk V, Maislos M, Oppert JM Executive Committee of the European Association for the Study of Obesity. Obesity: the gateway to ill health - an EASO position statement on a rising public health, clinical and scientific challenge in Europe. Obes Facts. 2013;6(2):117-20.

2. World Health Organization. Media centre. Obesity and overweight [Internet]. Geneva: WHO; 2015 [cited 2015 Aug 19]. Available from: http:// www.who.int/mediacentre/factsheets/fs311/en/index.html.

3. Matoulek M, Svačina Š, Lajka J. The incidence of obesity and its complications in the Czech Republic. Vnitr Lek. 2010 Oct.;56(10):1019-27. (In Czech.)

4. De Onis M. WHO child growth standards: length/height-for-age, weightfor-age, weight-for-length, weight -for-height and body mass index-forage: methods and development. Geneva: WHO; 2006.
5. Cole TJ, Lobstein T. Extended international (IOTF) body mass index cut-offs for thinness, overweight and obesity. Pediatr Obes. 2012 Aug;7(4):284-94.

6. Vignerová J, Lhotská L, Bláha P. Proposed standard definition for child overweight and obesity. Cent Eur J Public Health. 2001 Aug;9(3):145-6.

7. Bláha $\mathrm{P}$, Lhotská L, Vignerová J, Bošková R. The 5th nation-wide anthropological study of children and adolescents held in 1991 (Czech Republic) - selected anthropometric characteristics. Cesk Pediatr. 1993 Oct.;48(10):621-30. (In Czech.)

8. Měkota K, Kovář R, Chytráčková J, Gajda V, Kohoutek M, Moravec R. Unifittest (6-60): guide for manual and computerized evaluation of basic motor performance and selected characteristics of bod building of youth and adults in the Czech Republic. Prague: Charles University, Faculty of Physical Education and Sport; 2002. (In Czech.)

9. Moravec R, Kasa J. Physical development and motor performance of 7-18 years old children and youth in Czechoslovakia. Sborník Vědecké rady ÚV ČSTV. 1990;(21):53-81. (In Czech.)

10. Groeneveld HB. Metric detection and definition of back shape and posture of the human. Stuttgart: Hippokrates Verlag; 1976.

11. Kendall MG. Rank correlation methods. London: Griffin; 1948.

12. Pearson K. Notes on the history of correlation. Biometrika. 1920;13(1):2545.

13. Vignerová J, Humeníková L, Brabec M, Riedlová J, Bláha P. Long-term changes in body weight, BMI, and adiposity rebound among children and adolescents in the Czech Republic. Econ Hum Biol. 2007 Dec;5(3):40925.

14. Kunešová M, Vignerová J, Pařízková J, Procházka B, Braunerová R, Riedlová $\mathrm{J}$, et al. Long-term changes in prevalence of overweight and obesity in Czech 7-year-old children: evaluation of different cut-off criteria of childhood obesity. Obes Rev. $2011 \mathrm{Jul}$;12(7):483-91.

15. Matusitz J, McCormick J. Sedentarism: the effects of Internet use on human obesity in the United States. Soc Work Public Health. 2012;27(3):250-69.

16. Smith JJ, Eather N, Morgan PJ, Plotnikoff RC, Faigenbaum AD, Lubans DR. The health benefits of muscular fitness for children and adolescents: a systematic review and meta-analysis. Sports Med. 2014 Sep;44(9):120923.

Received August 14, 2014 Accepted in revised form April 10, 2015 